* Corresponding author. Tel.: +86-10-61772011; fax: +86-10-61772011.

\section{Yuanyuan $\mathrm{Li}^{*}$, Yongping Yang}

Power University, Beijing 102206, P.R. China

16
\section{(1)} \section{8} 9

School of Energy, Power and Mechanical Engineering, North China Electric 
Integrated solar combined cycle (ISCC) systems coupled with direct steam generation (DSG) are more promising in terms of system efficiency and electricity cost than current solar-only power generation systems, as ISCC-DSG offers the advantages of higher net thermal efficiency and lower cost. However, the ISCC systems usually have to be operated at part-load conditions with low system efficiency when no or lower insolation than that at design point is available as most of state-of-the-art such systems have no thermal storage equipped. In order to improve system performance and prolong the system full-load operation hours, a proper solar field size represented as the solar multiple is a prime parameter to be determined during the design stage of the ISCC system. A too large solar multiple might cause the collected solar thermal energy to become partially useless without thermal storage and high investment cost, while a smaller one might worsen the part-load performance of the system. This paper presents the thermodynamic and economic analysis for an ISCC system with two pressure level DSG solar fields (ISCC-2DSG), aiming to study the impacts of solar multiples on system performance with or without consideration of thermal storage. In the ISCC-2DSG system, the solar thermal energy produced from two solar fields is only used to supply latent heat for low- and high-pressure water vaporization, respectively. Feedwater preheating and steam superheating are achieved in a HRSG. The annual thermodynamic performance of several such ISCC-2DSG systems, with different solar multiple values but with identical design parameters in the power subsystem, is characterized. Based on these features, the $L E C$ for each system is 
1 calculated and compared. An optimum solar field size (solar multiple), which gives

2 the minimum $L E C$, for the ISCC-2DSG system can be finally obtained.

3

4 Keywords:

$5 \quad$ ISCC system, DSG technology, Solar multiple, Thermal storage

6

7

8

9

10

11

12

13

14

15

16

17

18

19

20

21

22 


\section{Introduction}

With the rapid depletion of fossil fuels and their adverse effects on the environment, the use of renewable energy sources needs to be accelerated. Solar energy is gaining more and more attention as a clean, free, and non-depleting source of energy [1]. Between 1984 and 1990, a total of nine Solar Electric Generating Systems (SEGS) were built in the Southern California desert. All these plants used an indirect steam generation technique, namely parabolic trough solar collectors, to heat up a heat transfer fluid (HTF) like oil. The HTF then transfers the heat to water or steam through heat exchangers. The working fluid (steam) produced eventually drives conventional Rankine cycles [2,3]. The introduction of intermediate heat exchangers to the systems results in a relatively high investment cost and the thermal losses associated with that layout.

To improve the efficiency of solar thermal power generation and to reduce cost, an Integrated Solar Combined Cycle System (ISCCS) was initially proposed by Luz Solar International in the early 1990s, as a means of integrating a parabolic trough solar field with a combined cycle power plant [4,5]. This integrated plant consists primarily of a conventional combined cycle plant, a solar collector field and a heat transfer fluid-to-water (or steam) heat exchanger. During the day, when solar heat is available, feed water is withdrawn from the combined cycle plant heat recovery steam generator (HRSG), heated by HTF and converted to saturated steam. The saturated steam is returned to the heat recovery steam generator to be superheated. With the solar heat input and same heating capacity in HRSG, the steam flow rate could be 
1 increased, thereby increasing the output of the Rankine cycle. During cloudy periods

2 or at night when solar heat is not available, the integrated plant operates as a

3 conventional combined cycle facility [3]. There are several thermal power plants

4 using this scheme, such as the ISCC projects in Algeria, Egypt, et al. [2,6,7]. Behar [2]

5 presented the performance of the first such integrated solar combined cycle system in

6 Algeria. The results showed that the power plant can produce about $134 \mathrm{MW}$ with the

7 fuel based net electricity efficiency equals $57.5 \%$ at night, and $157 \mathrm{MW}$ and $67 \%$ at

8 daytime. Horn [6] carried out an economic analysis of an ISCC power plant in Egypt

9 and concluded that "ISCC system provided an environmentally beneficial and

10 economically attractive option for renewable power generation in Egypt". The results

11 showed that 25,000 tons of $\mathrm{CO}_{2}$ emission could be reduced per year compared with

12 the reference fossil fired combined cycle (CC) power plant and the levelised

13 electricity cost $(L E C)$ was estimated to be $0.031 \$ / \mathrm{kWh}$.

14 A direct steam generation (DSG) solar field was then developed for the ISCC

15 system. The DISS (Direct Solar Steam) project was initiated by Zarza in 1996 [8],

16 aiming to reduce the cost by eliminating the heat exchangers. It was estimated that an

17 ISCC with DSG system could reduce the levelized electricity cost (LEC) by $10 \%$

18 when the DSG process is combined with improved components of the solar collectors 19 [9].

20 DSG technology presents some advantages when compared with HTF technology.

21 Parabolic troughs are cooled by HTF (oil), so an intermediate oil-to-water (or steam) 22 heat exchanger is needed between the solar field and the power block. This particular 
1 configuration is called HTF technology [10]. There is no need for an intermediate heat

2 exchanger between the solar field and the steam cycle in DSG configuration, resulting

3 in lower investment costs. Thermal and exergy losses associated with the heat

4 exchanger are also avoided, resulting in improvements in the overall efficiency.

5 Nezammahalleh et al. [11] studied three cases: an integrated solar combined cycle

6 system with DSG technology (ISCCS-DSG), a solar electric generating system

7 (SEGS), and an integrated solar combined cycle system with HTF technology

8 (ISCCS-HTF). This study showed that ISCCS-DSG had higher solar

9 heat-to-electricity net efficiency in comparison with ISCCS-HTF because of higher

temperature levels in the solar field. $\mathrm{CO}_{2}$ emission for the ISCCS-DSG is about $2.5 \%$

11 lower than that for ISCCS-HTF. The levelized electricity cost (LEC) for the ISCCS-DSG is the lowest among three systems. Cau et al [12] carried out a study on performance and cost assessment of Integrated Solar Combined Cycle Systems using

$14 \mathrm{CO}_{2}$ as the heat transfer fluid. The results show that the use of $\mathrm{CO}_{2}$, instead of the more conventional thermal oil, as a heat transfer fluid allows for an increase in the temperature of the heat transfer fluid and thus in solar energy conversion efficiency.

17 The solar energy conversion efficiency ranges from $23 \%$ to $25 \%$ for a $\mathrm{CO}_{2}$ maximum temperature of $550{ }^{\circ} \mathrm{C}$. This is similar to the predicted conversion 19 efficiencies of the direct steam generation solar plants $(22-27 \%)$. cost than a solar-only system [13]. ISCC-DSG does not usually require thermal storage when the direct normal irradiance $(D N I)$ is low or nil because the basic power 
1 output level can be assured in the power subsystem. However, like all other solar

2 systems, the performance of the ISCC system depends on solar radiation, which can

3 vary significantly. There are times when the systems run under part-load conditions,

4 resulting in a compromise of the system efficiency. In order to accomplish the

5 nominal power output for a longer time period, the solar field is normally oversized.

6 The degree of oversize is termed as a solar multiple, which is defined as the ratio of

7 the solar thermal energy produced by the solar field to that required by the power

8 block at the design point [14].

9 Solar multiple is a prime parameter which should be determined at the design stage.

10 If the solar multiple chosen was too big for a system without thermal storage, it would

11 cause collected solar energy to be wasted alongside unnecessarily high investment costs. A small solar multiple would make the system work under part-load conditions

13 for a longer time period. This paper conducts a thermo-economic analysis to study the 14 impacts of solar multiples on the performance of ISCC systems with two 15 pressure-level DSG fields (ISCC-2DSG). The annual thermodynamic performances of

\section{System configuration description}

The ISCC system adopted in this study is configured based on a reference combined cycle gas turbine (CCGT). The reference CCGT plant consists primarily of 
1 a General Electric 7FA gas turbine [15], a dual-pressure, single reheat, steam turbine

2 and a heat recovery steam generator (HRSG). Two DSG solar fields at different

3 pressure levels are added into the reference plant to form the proposed novel

4 ISCC-2DSG system as shown schematically in Fig. 1a. The steam reheating process is

5 not shown in Fig. 1 to keep the schematic diagram clear. Besides the two DSG

6 coupling the other feature of the proposed ISCC-2DSG system is that the solar

7 thermal energy produced is used to supply latent heat for feedwater vaporization only.

8 In other words, solar heat is not used to supply sensible heat for heating feed water (to

9 saturated state) or steam superheating.

10 Feedwater from the deaerators is pumped to the low- and high-pressure

11 economizers to be preheated in the HRSG, and then sent to the solar fields, where it is

12 vaporised.

13 DSG solar fields at two different pressure levels are used to produce low- and 14 high-pressure saturated steam, respectively. The saturated steam generated from DSG 15 solar fields returns to the HRSG to be superheated to the live steam temperature by 16 the exhaust gas in superheater, and then feeds into the steam turbine. Due to the solar 17 heat contribution and constant heating capacity in HRSG, the water (or steam) mass

18 flow rate can be increased. Thus the steam turbine and condenser of the ISCC-2DSG 19 system have to be bigger than the corresponding parts of the reference combined cycle 20 power plant.

21 The study to find the desirable solar multiple for the ISCC-2DSG system is based on previous work where the HRSG and steam turbine working parameters have been 
1 optimized to match the solar integration [16]. The increase in solar multiples

2 represents a larger solar field and higher capital investment required [17]. Also, the

3 increase in solar multiples represents an increase in the solar thermal energy produced.

4 Since the solar thermal energy generated in excess of that required at nominal

5 conditions can be stored and used in the power subsystems by including a thermal

6 storage, a comparative analysis is essential to study the impacts of solar multiples on

7 the performance of ISCC-2DSG systems with or without thermal storage.

\section{Performance criteria}

The following performance indicators are defined and used to reveal the performance of the ISCC-2DSG system.

$$
S M_{\text {design-point }}=\left.\frac{Q_{t h, \text { solar-field }}}{Q_{t h, \text { power-block }}}\right|_{\text {design-point }}
$$

where $Q_{\text {th,solar-field }}$ is the solar thermal energy produced by the solar field at the design

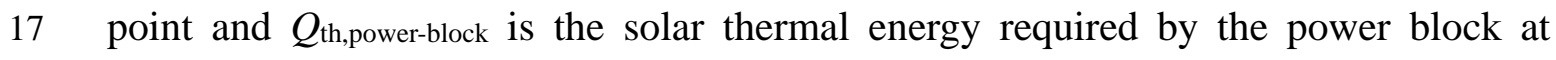
nominal conditions. The greater the solar multiple, the larger solar field area is required.

20 For a solar system with thermal storage, the number of operational hours at nominal

21 conditions would increase when compared with one without thermal storage. When the solar multiple increases, the annual full load operational hours increase as well. 
1 The system capacity factor $(C F)$ is defined as the ratio of annual net electricity

2 production to the maximum annual electricity that can be produced:

3

$4 \quad C F=\frac{E_{n e t, a}}{8760 \cdot W_{n e t}}$

6 where $E_{\text {net,a }}$ is the annual net electricity production, $W_{\text {net }}$ is the system net power

7 output at nominal conditions. $8760 \mathrm{~h}$ is the hours per year. If the system operates at nominal conditions full year, the annual net power output is defined as the maximum

9 annual electricity.

10 The annual thermal efficiency of the whole system $\eta_{\text {th,a }}$ is defined as:

$$
\eta_{t h, a}=\frac{E_{n e t, a}}{8760 \cdot Q_{f}+Q_{a b s, a}}=\frac{E_{n e t, a}}{8760 \cdot m_{f} \cdot L H V+Q_{a b s, a}}
$$

where $Q_{\mathrm{f}}=m_{\mathrm{f}} \cdot L H V$ is the fuel low heating value input, $Q_{\mathrm{abs}, \mathrm{a}}$ is the annual solar heat absorbed by the steam.

16 The contribution of the low and mid temperature level solar heat can be measured by its share in the system annual total thermal energy input:

$$
X_{s o l, a}=\frac{Q_{a b s, a}}{8760 \cdot Q_{f}+Q_{a b s, a}}=\frac{Q_{a b s, a}}{8760 \cdot m_{f} \cdot L H V+Q_{a b s, a}}
$$

21 To evaluate the performance of the solar heat conversion in the proposed system, 
1 the annual solar-to-electricity efficiency, based on reference [18], is defined as:

$3 \quad \eta_{s o l, a}=\frac{E_{n e t, a}-E_{r e f, a}}{Q_{r a d, a}}$

5 where $E_{\text {ref,a }}$ is the annual net power output generated by a reference system with the

6 same natural gas input. In this study, a conventional natural gas fired combined cycle

7 power plant (CCGT) is chosen as a reference system. $Q_{\text {rad,a }}=Q_{\mathrm{abs}, \mathrm{a}} / \eta_{\mathrm{col}, \mathrm{a}}$ represents the

8 annual total solar insolation incident on the solar concentrator, $\eta_{\mathrm{col}, \mathrm{a}}$ is the annual

9 collector efficiency.

10 Compared with a conventional combined cycle system, the annual fossil fuel 11 savings for generating the same amount of electricity is defined as the annual fossil 12 fuel saving ratio:

$14 \quad S R_{f, a}=\frac{Q_{r e f, a}-8760 \cdot Q_{f}}{Q_{r e f, a}}=1-\frac{8760 \cdot Q_{f} \cdot \eta_{t h, r e f}}{E_{n e t, a}}$

where the numerator $\left(Q_{\text {ref,a }}-8760 \cdot Q_{\mathrm{f}}\right)$ denotes how much annual fossil fuel input can

17 be saved to produce the same annual power output as the reference system $\left(Q_{\text {ref,a }}=\right.$ $\left.18 E_{\text {net,a }} / \eta_{\text {th,ref }}\right), \eta_{\text {th,ref }}$ is the annual thermal efficiency for the reference system.

\section{Annual performance analysis}


The ISCC-2DSG systems with different solar field sizes (different solar multiples) were simulated by using the ASPEN PLUS code [19]. The component models are based on the energy balance, mass balance, and species balance, with a default relative convergence error tolerance of $0.01 \%$, which is the specified tolerance for all tear convergence variables. The RK-SOAVE and STEAM-TA equations were applied to calculate the thermodynamic properties of gas and water, respectively. The General Electric 7FA gas turbine was selected for the simulation. Natural gas was used as the fuel and dry, low $\mathrm{NO}_{\mathrm{x}}$ combustion technology was applied. In addition, the cooled turbine model presented in a previous work [20] was used. The steam power block mainly consists of high pressure (HP) and low pressure (LP) steam turbines. A single reheat stage is considered in order to improve the average turbine temperature and steam dryness.

The solar field is an array of parabolic trough direct steam generation (DSG) collectors of ET-150 (Euro trough collectors). The main technical parameters for the collector loop for the simulation are given in reference [16]. The design point parameters of the solar field are given in Table 1. The location selected for this investigation is Yulin, in Shaanxi province, China, with an elevation of $1058 \mathrm{~m}$. The ambient temperature for the calculation was $25^{\circ} \mathrm{C}$. The $D N I$ of the design point is set at $800 \mathrm{~W} / \mathrm{m}^{2}$. The annual performance is based on the daily operation of the system during typical days chosen from every month of the year. The main assumptions used in the simulation are summarized in Table 2, most of which are cited from reference [21]. 
In this study, the solar dispatching operation mode was selected. During sunshine hours, the system works as an ISCC-2DSG power plant. When solar energy is unavailable, the ISCC-2DSG operates as a conventional CC power plant at off-design conditions. Specifically, the gas turbine is assumed to operate continuously at the full load. The electricity output of the steam turbine mainly depends on the solar field configuration and the weather conditions, and other parameters. When the heat needed for evaporating water at nominal conditions is available from solar field (without thermal storage) or both from solar field and thermal storage system (with thermal storage), the steam turbine operates at the full load, or else, at part-load conditions.

\subsection{Performance analysis and comparison}

In the previous work, it was concluded that for the given ISCC-2DSG with fixed live steam pressure, the optimum pressure and temperature of the reheat steam and secondary steam at the design point are: 16 bar and $560{ }^{\circ} \mathrm{C}$, and 5 bar and $320{ }^{\circ} \mathrm{C}$, respectively [16]. With these parameters, solar multiples, ranging from 1 to 1.5 , have been selected as the design parameter and optimized for the given ISCC-2DSG system with and without thermal storage, respectively. Both solar fields are changed at the same rate. For each case, the threshold for the solar field to be linked to the power plant is that the $D N I$ is equal to or greater than $250 \mathrm{~W} / \mathrm{m}^{2}$.

\subsubsection{Annual simulation results for cases without thermal storages}

The simulated annual performance of the ISCC-2DSG system without thermal 
storage is given in Table 3. Figure 2 exhibits the effect of solar multiples on the annual solar thermal share, annual solar-to-electricity efficiency and annual fossil fuel saving ratio. Figure 3 presents the impact of solar multiples on the system capacity factor and annual thermal efficiency. The annual thermal efficiency is considered to be the most important, which is defined as the annual net electricity production divided by the annual total thermal energy input to the system, including both fuel and solar heat. Another key parameter for system performance assessment is the system capacity factor, which is calculated by the ratio of annual electricity production to the maximum annual electricity that can be produced.

As the gas turbine is assumed to operate continuously at full load, the annual fuel consumption is a constant. When the solar multiple increases, the annual solar thermal energy input becomes greater, leading to more annual net electricity production, and higher annual full load operation hours (defined as the ratio of annual electricity production to the system net power output at nominal conditions). This is because with bigger multiples, the solar heat collected could still reach the required threshold to run the power block at the design point, even when the DNI is below the designed value $\left(800 \mathrm{~W} / \mathrm{m}^{2}\right)$. As a result, longer full load operation times could be realized.

When the solar multiple increases, both the annual electricity generation and the annual solar insolation incident on the solar concentrator enhance. Since the increasing rate of the annual electricity generation is larger than that of the annual solar insolation incident on the solar concentrator, the annual solar thermal share, annual solar-to-electricity efficiency and annual fossil fuel saving ratio all increase 
1 with the enhancement of the solar multiple, as can be observed in Fig. 2. From Fig. 3,

2 it can be seen that as the solar multiple increases, the capacity factor increases because

3 the solar thermal energy is in surplus. Notably, from the annual thermal efficiency

4 point of view, the optimum solar multiple is 1.3 for the ISCC-DSG system, which 5 gives a peak annual net thermal efficiency of $54.09 \%$.

\subsubsection{Annual simulation results for cases with thermal storage}

A larger solar multiple for ISCC-2DSG systems without thermal storage would lead to the solar thermal energy collected being wasted. To reduce the investment, conventional integrated solar combined cycle power plants commonly do not have thermal storage facilities. However, the integrated power plant generally operates at part load due to the variable weather conditions, leading to poor system performance and stability. If an ISCC-2DSG system was equipped with thermal storage, the full-load electricity generation could continue even when the sun is not shining. Also, for large solar multiples, if the solar thermal energy produced more than the nominal requirements of the power block, this excess, which is able to be used for electricity generation, can be stored in the thermal storage subsystem. All the stored solar heat would be used to extend the production period, in order to minimize the system start and stop, thereby improving the system stability. The thermal storage facilities could not only extend the full load operational time, but also add electricity generation from the stored solar heat even when solar energy is not available. However, adding thermal storage would inevitably lead to an increased capital investment, therefore, 
1 the optimization of the thermal storage and solar multiples is essential to achieve the

2 best economic outcome for the ISCC-2DSG system. A thermal storage system using

3 phase change materials (PCMs) seems thermodynamically and economically

4 favorable to store the latent heat of an evaporation process [22]. PCMs absorb energy

5 as the phase change occurs during the evaporation process and then can release this

6 energy during condensation [23] at a constant temperature. A driving temperature

7 difference of $10{ }^{\circ} \mathrm{C}$ is set for the heat transfer from the steam to the PCM for charging

8 and from the PCM to the water for discharging. The water evaporation at two different

9 pressures in the ISCC-2DSG system can be facilitated by using sodium nitrate

$10\left(\mathrm{NaNO}_{3}\right)$ with a melting temperature of $307^{\circ} \mathrm{C}$ and mannitol with a melting

11 temperature of $165^{\circ} \mathrm{C}$ [23]. The proposed ISCC-2DSG system with thermal storage is

12 shown in Fig. 1b. The surplus solar thermal energy produced, used to evaporate water,

13 is converted to the steam latent heat and then stored in a phase change material (PCM).

14 During charging, PCM melts at a constant temperature by absorbing heat from the

15 steam produced in the solar field. When the solar thermal energy produced is lower

16 than the nominal demand or no solar radiation is available, discharging process, in

17 which the PCM freezes by releasing heat for evaporating water, occurs. In the analysis,

18 the storage capacity was varied in parallel with the solar multiple. For a given solar

19 multiple, thermal storage size was big enough to store the excess solar thermal energy

20 produced at design point.

21 Table 4 exhibits the annual performance results of the ISCC-2DSG system with 
1 solar thermal share, annual solar-to-electricity efficiency and annual fossil fuel saving

2 ratio (Fig.4), capacity factor and annual thermal efficiency (Fig.5), respectively. With

3 the solar multiple increasing more solar thermal energy is generated, used and stored.

$4 \quad$ As the stored solar heat can be used during non-insolation hours, the operational hours

5 of the ISCC-2DSG are greater than those for cases without thermal storage.

$6 \quad$ Figure 4 shows that the annual solar thermal share and annual fossil fuel saving 7 ratio increase with the solar multiple. Annual solar-to-electricity efficiency peaks 8 when the solar multiple is 1.3 . Figure 5 shows the effect of the solar multiple on the 9 capacity factor and annual thermal efficiency. The capacity factor is larger than that of the system without thermal storage. The annual thermal efficiency peaks at $54.66 \%$

11 when the solar multiple is 1.2 , which is $0.57 \%$-points higher than that of the system 12 without thermal storage. When the solar multiple is over 1.2 , the annual thermal 13 efficiency sharply decreases because the increase in the annual solar heat input 14 predominates over the increase in the annual electricity generation. Obviously a solar 15 multiple of 1.2 is the optimum value for this case in terms of annual thermal efficiency.

17 When Tables 3 and 4 are compared, it can be seen that the system with thermal storage presents a better thermodynamic performance than that without thermal 19 storage at the same solar multiple, since the surplus solar thermal energy produced could be stored and utilized effectively. The system without thermal storage appears to favor larger solar multiples than the one utilizing thermal storage. Perhaps it can be explained as that at the given location, there are more hours during which the solar 
1 radiation is lower than the designed nominal values. Therefore, to achieve longer

2 nominal electric power output, solar multiple is always greater than one for any solar

3 field designs. In the cases without thermal storage, a larger solar multiple is needed to

4 prolong nominal operation times in order to accomplish an optimal annual electric

5 power output. However, the cost of electricity would be higher for such a big solar

6 multiple. Economics should also be considered to obtain the optimal solar multiple.

7

8

9

\section{Economic analysis}

Bigger solar multiples and thermal storage would improve the system's thermodynamic performance. However, they arouse higher costs. A cost-effect analysis is necessary for comprehensibly assessing the overall system performance. Based on the annual performance results, the levelized electricity cost ( $L E C)$, which depends on the total investment costs, operation and maintenance costs, fuel cost and annual electricity production, can be calculated for all the solar multiples considered. The levelized electricity cost $(L E C)$ is calculated by:

$7 \quad L E C=\frac{f c r \cdot C_{T P C}+C_{O \& M}+C_{\text {fuel }}}{E_{\text {net }, a}}$

where $E_{\text {net,a }}$ is the annual net electricity production, $f c r \cdot C_{\mathrm{TPC}}$ represents annual investment cost and $f c r$ is capital recovery factor, which can be calculated by: 


$$
1 \quad f c r=\frac{i \cdot(1+i)^{n}}{(1+i)^{n}-1}=8.88 \%
$$

where $i$ is the loan interest rate, $n$ is the plant lifetime (assumed to be $30 \mathrm{y}$ ), $C_{\mathrm{TPC}}$ is the total plant cost, Co\&m is the annual operation and maintenance costs (which can be

expressed as a percentage of total plant cost: $5 \%, 2 \%$ and $1.5 \%$ of the investment cost in a gas, steam and solar unit, respectively) [24]. $C_{\text {fuel }}$ is the annual fuel cost: the natural gas price is set to be $7.6 \$ / \mathrm{GJ}$. The price of electricity is $0.08 \$ / \mathrm{kWh}[21]$.

The economic assumptions for calculating the $L E C$ are shown in Table 5, which have been set according to several references [10,11,21].

Figures 6 and 7 present the levelized electricity cost as a function of the solar multiple, with or without thermal storage, respectively. It can be seen in both cases that there is a minimum $L E C$ existing with a proper solar multiple. As mentioned before, increasing the solar multiple would cause higher investment cost. The main costs of the power plant are the solar field, the power block and the storage equipment. The solar multiple with or without thermal storage impacts on both the thermodynamic and economic performances of the power system, therefore its thermo-economic analysis is essential to balance the overall system properties.

8 It can be observed in Fig. 6, that as the solar multiple increases, the increasing rate of annual net electricity production is larger than that of the investment, leading to a decrease in the $L E C$. When the solar multiple is over 1.3, the increase in system investment overtakes and a larger solar field (solar multiple) would not create a predominant increase in annual electricity production. Therefore the larger solar field 
1 size would not be cost effective. The system without thermal storage can attain a

2 minimum $L E C$ of $0.063 \$ / \mathrm{kWh}$ when the solar multiple is 1.3 , while the system with

3 thermal storage has a minimum $L E C$ of $0.064 \$ / \mathrm{kWh}$ when the solar multiple is 1.2 ,

4 as shown in Fig. 7. The results are in line with the optimum solar multiple (1.3 for

5 system without thermal storage and 1.2 for that with thermal storage) in terms of

6 annual thermal efficiency, as discussed previously. Generally, this preliminary

7 economic analysis has been carried out based on some reference data shown in

$8 \quad[10,11,21,25]$. The $L E C$ values can be changed depending on each specific case, for

9 which the investment, O\&M costs, etc. are different.

10 In addition, it can be observed that for a given solar multiple value, the $L E C$ is

11 higher for systems with thermal storage than for those without, since the thermal

12 storage cost accounts for a significant part of the $L E C$ calculation. The optimum solar

13 multiple for the system without thermal storage is higher than for that with thermal

14 storage. For an ISCC-2DSG system with thermal storage, although it requires high

15 investment, the waste of the solar heat collected is lower than that of a system without

16 thermal storage, so a smaller solar field size is required.

\section{Conclusions}

This paper presents a parametric study on the solar multiples for a proposed integrated solar combined cycle system with two direct steam generation solar fields (ISCC-2DSG). ISCC-2DSG systems with solar multiples of 1, 1.1, 1.2, 1.3, 1.4 and

1.5 , with or without thermal storage, are simulated. The performance of each case is 
1 characterized under design-point and yearly conditions. Since the annual system

2 performance is assessed, the levelized electricity cost (LEC) for each system can be

3 determined and compared, revealing the optimum solar field size for which a

4 minimum levelized electricity cost can be achieved.

5 The ISCC system analyzed in the paper consists primarily of DSG parabolic trough

6 solar fields coupled to the bottoming steam cycle of a conventional combined cycle

7 gas turbine system. The power block mainly contains a 7FA gas turbine and dual

8 pressure single reheat steam cycle. In the calculation, the ISCC-2DSG system

9 operates in a solar dispatching mode: the gas turbine runs at full load for 24 hours,

10 neglecting the effect of ambient temperature variations and the steam turbine is

11 enlarged to accommodate the solar thermal energy input.

12 The optimum solar multiple values for the ISCC-2DSG system with and without thermal storage have been found, respectively. This investigation, which has been carried out using the ASPEN PLUS code, finds that: capacity factor increases due to greater electricity production. The optimum solar multiple is 1.3 , which would give a peak annual thermal efficiency of $54.09 \%$ and a best $L E C$ of $0.063 \$ / \mathrm{kWh}$; cases without thermal storage owing to the effective utilization of the surplus solar thermal energy generated. A maximum annual thermal efficiency of $54.66 \%$ and a minimum $L E C$ of $0.064 \$ / \mathrm{kWh}$ could be obtained, when the solar multiple is 1.2 ; 
3) Large solar field sizes, i.e. solar multiples, especially those with thermal storage,

2 undoubtedly prolong the system's full-load operational hours and thus improve the

3 system's thermal performance. However, they inevitably carry higher investment cost.

4 For a given solar multiple, the $L E C$ for the system with thermal storage is higher than

5 that of the system without thermal storage. Thus, thermal storage is not favorable

6 economically for an ISCC-2DSG system, which weakens its advantages on overall

7 performance improvements.

8

$9 \quad$ Nomenclature

$10 \quad C \quad$ Cost $[\$]$

11 CCGT Combined cycle gas turbine

$12 \quad C F \quad$ Capacity factor

13 DNI Direct normal irradiation $\left[\mathrm{W} / \mathrm{m}^{2}\right]$

14 DSG Direct steam generation

$15 E_{\text {net,a }} \quad$ Annual net electricity production [MWh]

$16 \quad f c r \quad$ Average annual investment coefficient

17 HTF Heat transfer fluid

$18 \quad i \quad$ loan interest rate

19 ISCC Integrated solar combined cycle

20 LEC Levelized electricity cost $[\$ / \mathrm{kWh}]$

$21 L H V \quad$ Lower heating value $[\mathrm{kJ} / \mathrm{kg}]$

$22 m \quad$ Mass flow $[\mathrm{kg} / \mathrm{s}]$ 


\begin{tabular}{|c|c|c|}
\hline 1 & $n$ & Plant lifetime $[y]$ \\
\hline 2 & $Q_{\mathrm{f}}$ & Fuel low heating value input [MW] \\
\hline 3 & $Q_{\mathrm{abs}, \mathrm{a}}$ & Annual absorbed solar heat [MWh] \\
\hline 4 & $Q_{\text {rad.a }}$ & Annual Solar energy irradiated to solar field [MWh] \\
\hline 5 & SEGS & Solar electric generating system \\
\hline 6 & $S M_{\text {design-point }}$ & Solar multiple at design-point \\
\hline 7 & $S R_{\mathrm{f}, \mathrm{a}}$ & Annual fossil fuel saving ratio \\
\hline 8 & $W_{\text {net }}$ & Nominal power output [MW] \\
\hline 9 & $X_{\text {sol,a }}$ & Annual solar thermal share \\
\hline 10 & $\eta_{\mathrm{col}, \mathrm{a}}$ & Annual solar collector efficiency \\
\hline 11 & $\eta_{\text {th,a }}$ & Annual thermal efficiency \\
\hline 12 & $\eta_{\text {sol,a }}$ & Annual solar-to-electricity efficiency \\
\hline 13 & & \\
\hline 14 & Subscript & \\
\hline 15 & $\mathrm{a}$ & Annual \\
\hline 16 & col & Solar collector \\
\hline 17 & f/fuel & Fossil fuel \\
\hline 18 & net & Net value \\
\hline 19 & O\&M & Operation and maintenance \\
\hline 20 & $\mathrm{rad}$ & Radiation \\
\hline 21 & ref & Reference system \\
\hline 22 & abs & Absorbed solar heat \\
\hline
\end{tabular}


th Thermal

2 TPC Total plant cost

\section{Acknowledgement}

The authors gratefully acknowledge support from the National Science Foundation (No. 51406049).

\section{References}

[1] Jamel MS, Abd Rahman A, Shamsuddin AH. Advances in the integration of solar thermal energy with conventional and non-conventional power plants. Renew Sust Energ Rev 2013; 20: 71-81.

[2] Behar O, Kellaf A, Mohamedi K, Belhamel M. Instantaneous performance of the first integrated solar combined cycle system in Algeria. Energy Pro 2011; 6: $185-93$.

[3] Baghernejad A, Yaghoubi M. Exergy analysis of an integrated solar combined cycle system. Renew Energ 2010; 35(10): 2157-64.

[4] Kelly B, Hermann U, Hale M. Optimization studies for integrated solar combined cycle systems. Sol Eng 2001; 393-8.

[5] Zhu G, Neises T, Turchi C, Bedilion R. Thermodynamic evaluation of solar integration into a natural gas combined cycle power plant. Renew Energ 2015; 74: 815-24.

[6] Horn M, Führing H, Rheinländer J. Economic analysis of integrated solar 
combined cycle power plants: A sample case: The economic feasibility of an ISCCS power plant in Egypt. Energy 2004; 29(5): 935-45.

[7] Behar O, Khellaf A, Mohammedi K, Ait-Kaci S. A review of integrated solar combined cycle system (ISCCS) with a parabolic trough technology. Renew Sust Energ Rev 2014; 39: 223-50.

[8] Zarza E, Valenzuela L, León J, Weyers H, Eickhoff M, Eck M, et al. The DISS project: Direct steam generation in parabolic troughs: Operation and maintenance experience-update on project status. Sol Eng 2001; 419-26.

[9] Eck M, Zarza E, Eickhoff M, Rheinländer J, Valenzuela L. Applied research concerning the direct steam generation in parabolic troughs. Sol Energy 2003; 74(4): $341-51$.

[10] Montes MJ, Rovira A, Muñoz M, Martínez-Val JM. Performance analysis of an integrated solar combined cycle using direct steam generation in parabolic trough collectors. Appl Energy 2011; 88(9): 3228-38.

[11] Nezammahalleh H, Farhadi F, Tanhaemami M. Conceptual design and techno-economic assessment of integrated solar combined cycle system with DSG technology. Sol Energy 2010; 84(9): 1696-705.

[12] Cau G, Cocco D, Tola V. Performance and cost assessment of integrated solar combined cycle systems (ISCCS) using $\mathrm{CO}_{2}$ as heat transfer fluid. Sol Energy 2012; 86: 2975-85.

[13] Rovira A, Montes MJ, Varela F, Gil M. Comparison of heat transfer fluid and direct steam generation technologies for integrated solar combined cycles. 
Appl Therm Eng 2013; 52(2): 264-74.

[14] Montes MJ, Abánades A, Martínez-Val JM, Valdés M. Solar multiple optimization for a solar-only thermal power plant, using oil as heat transfer fluid in the parabolic trough collectors. Sol Energy 2009; 83(12): 2165-76.

[15] Gas turbine world 2010 handbook. USA: Pequot Publishing, Inc.; 2010.

[16] Li Y, Yang Y. Thermodynamic analysis of a novel integrated solar combined cycle. Appl Energy 2014; 122: 133-42.

[17] Coelho B, Varga S, Oliveira A, Mendes A. Optimization of an atmospheric air volumetric central receiver system: Impact of solar multiple, storage capacity and control strategy. Renew Energy 2014; 63: 392-401.

[18] Hong H, Jin H, Ji J, Wang Z, Cai R. Solar thermal power cycle with integration of methanol decomposition and middle-temperature solar thermal energy. Sol Energy 2005; 78: 49-58.

[19] Aspen Plus®. Aspen Technology, Inc., Version 11.1[EB/OL]-Available at: <http://www.aspentech.com/> [accessed 5.1.2009].

[20] Abdallah H, Harvey S. Thermodynamic analysis of chemically recuperated gas turbines. Int J Therm Sci 2001; 40: 372-84.

[21] Luo C, Zhang N. Zero $\mathrm{CO}_{2}$ emission SOLRGT power system. Energy 2012; 45: 312-23.

[22] Laing D, Bahl C, Bauer T, Lehmann D, Steinmann W. Thermal energy storage for direct steam generation. Sol Energy 2011; 85(4): 627-33.

[23] Pielichowska K, Pielichowski K. Phase change materials for thermal energy 

storage. Prog Mater Sci 2014; 65: 67-123.

2

[24] Hosseini R, Soltani M, Valizadeh G. Technical and economicassessment of the integrated solar combined cycle power plants in Iran. Renew Energy 2005; 30: 1541-55.

[25] Montes MJ, Abánades A, Martínez-Val J M. Performance of a direct steam generation solar thermal power plant for electricity production as a function of the solar multiple. Sol Energy 2009; 83(5): 679-89.

8

(1)

0

1

2

3

14

5

6

7




\section{$1 \quad$ List of Figures}

2 Fig. 1a Schematic diagram of an ISCC system with two DSG solar fields without thermal storage

Fig. 1b Schematic diagram of an ISCC system with two DSG solar fields with thermal storage

Fig. 2 Influence of solar multiples on annual solar thermal share, annual solar-to-electricity efficiency and annual fossil fuel saving ratio without thermal storage

Fig. 3 Effect of solar multiples on capacity factor and annual thermal efficiency without thermal storage

Fig. 4 Influence of solar multiples on annual solar thermal share, annual solar-to-electricity efficiency and annual fossil fuel saving ratio with thermal storage

Fig. 5 Effect of solar multiples on capacity factor and annual thermal efficiency with thermal storage

Fig. 6 Variation in levelized electricity cost for every solar multiple without thermal storage

Fig. 7 Variation in levelized electricity cost for every solar multiple with thermal storage 


\section{$1 \quad$ List of Tables}

2 Table 1 Design point parameters for the DSG solar fields of an ISCC system

3 Table 2 Main assumptions for the simulation and calculation

4 Table 3 Annual performance simulation results for ISCC-2DSG systems without

5 thermal storage

6 Table 4 Annual performance simulation results for ISCC-2DSG systems with 7 thermal storage

8 Table 5 Cost data for economic analysis

9

10

11

12

13

14

15

16

17

18

19 


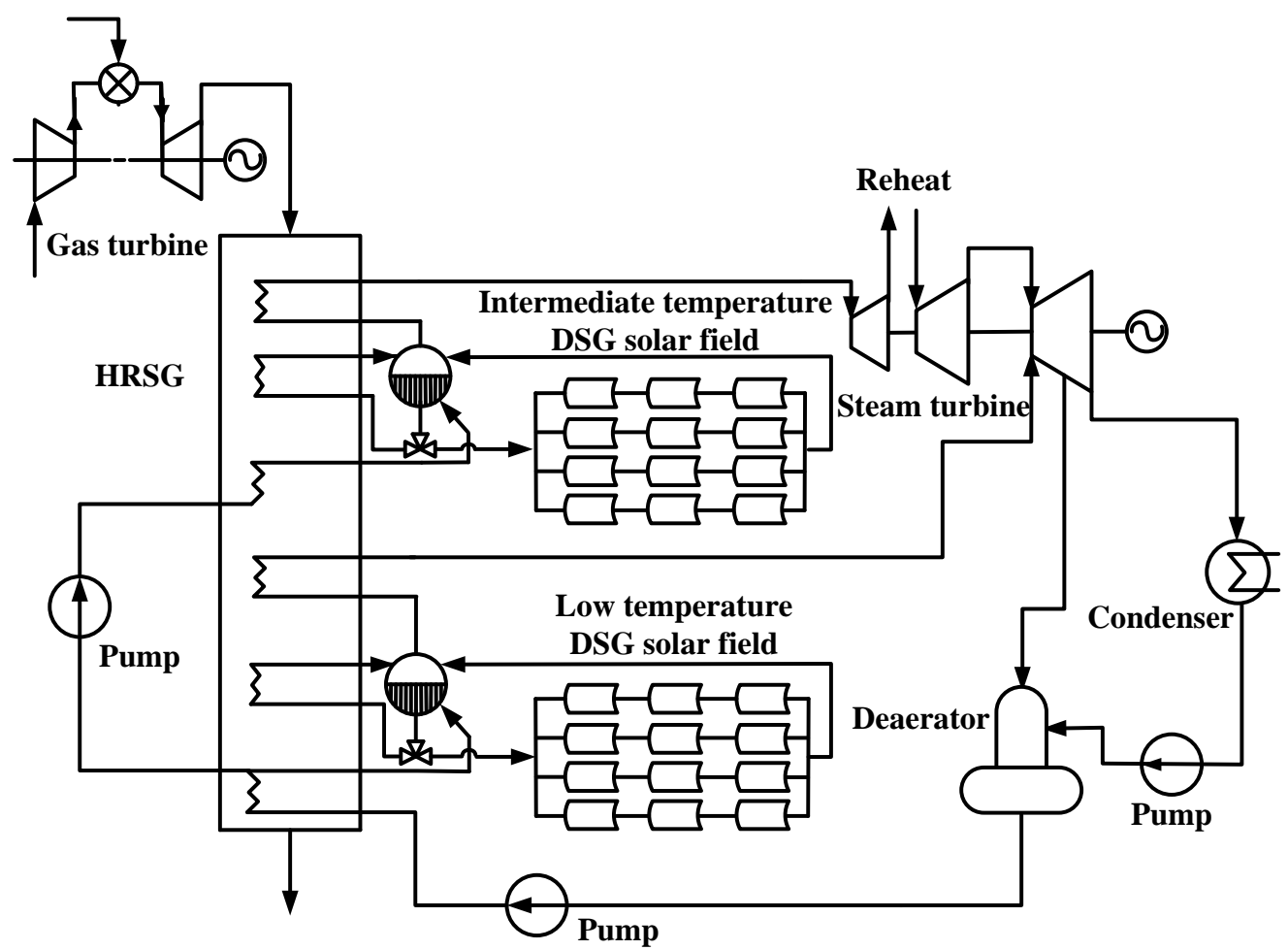

Fig. 1a Schematic diagram of an ISCC system with two DSG solar fields without thermal storage

西

西

(




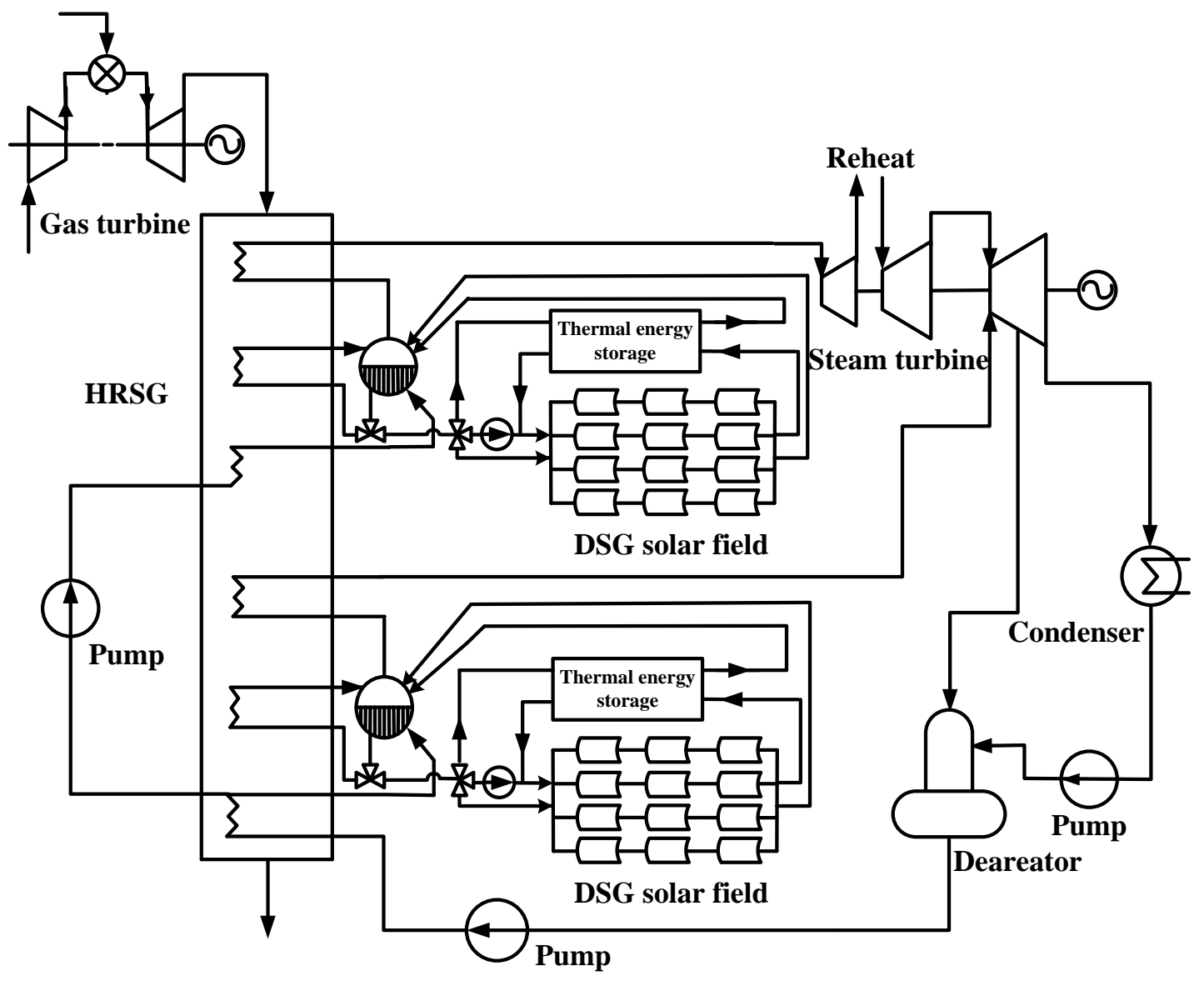

Fig. 1b Schematic diagram of an ISCC system with two DSG solar fields with thermal storage 


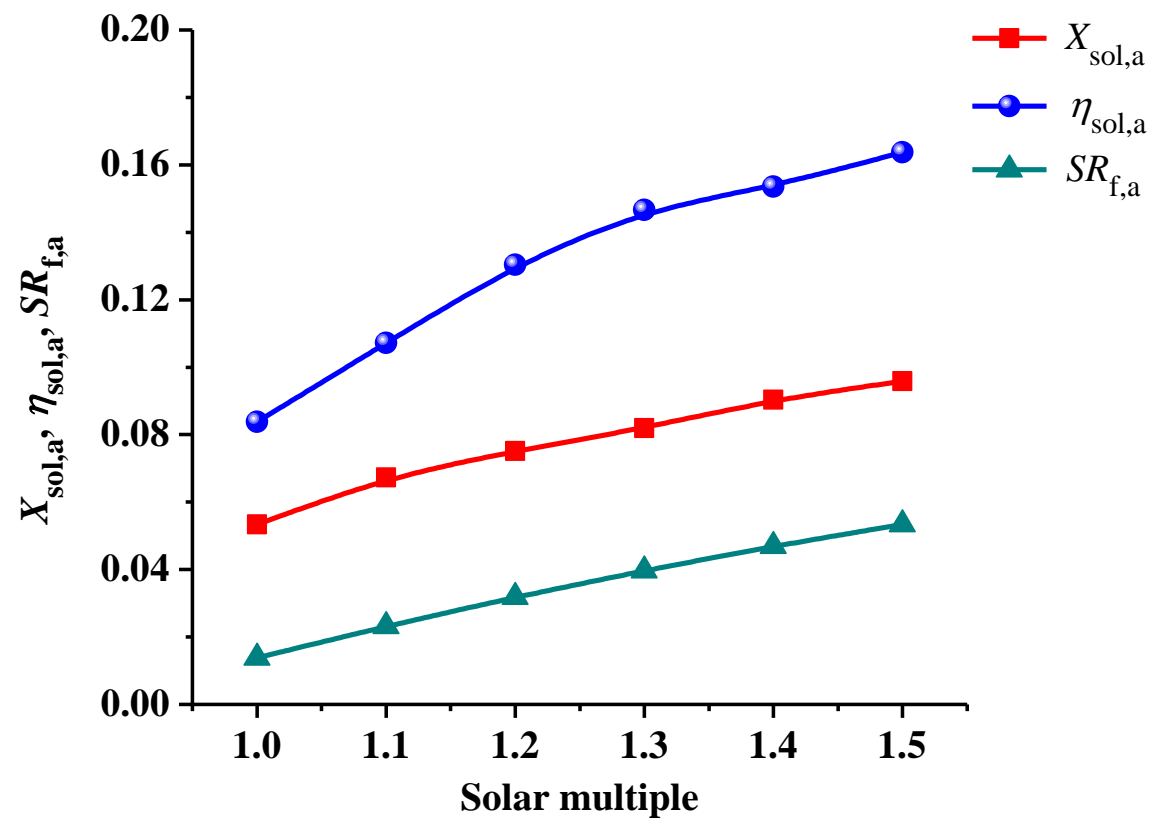

1

Fig. 2 Influence of solar multiple on annual solar thermal share, annual

3 solar-to-electricity efficiency and annual fossil fuel saving ratio without thermal 


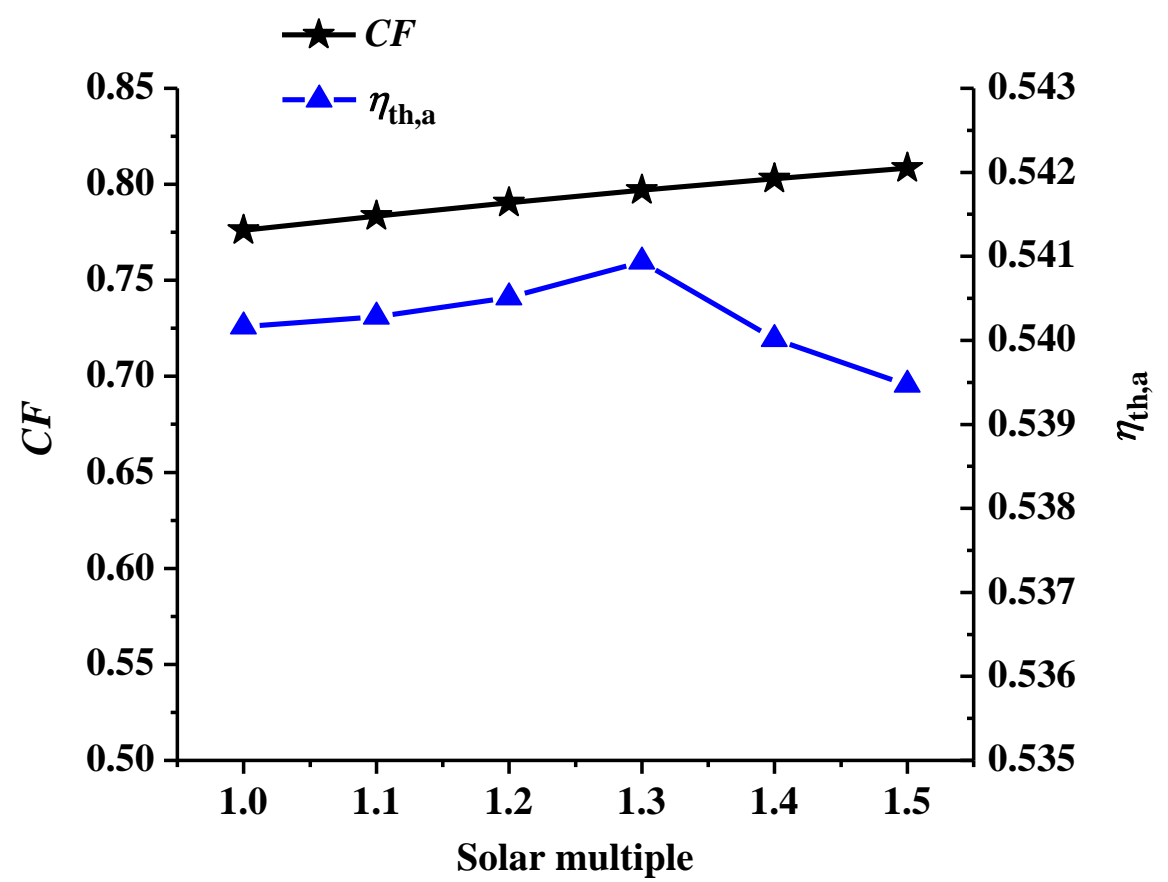

1

2 Fig. 3 Effect of solar multiple on capacity factor and annual thermal efficiency

without thermal storage

4

5

6 


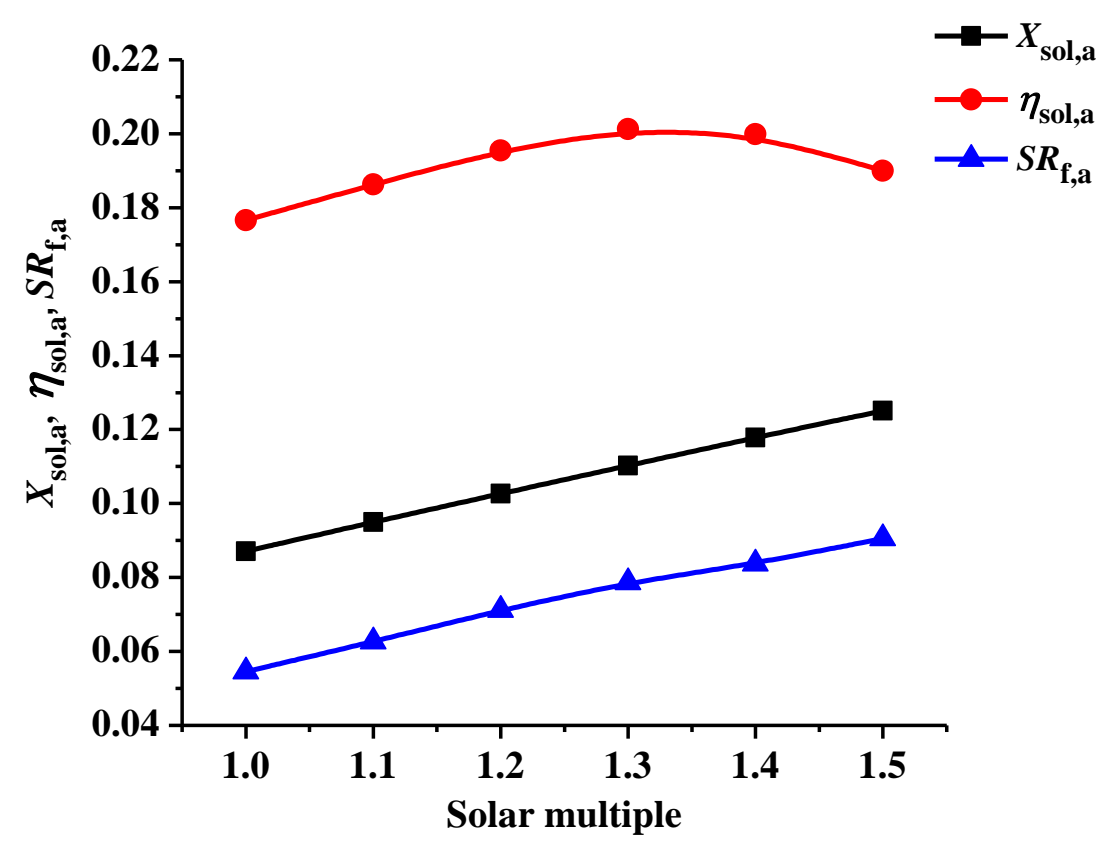

Fig. 4 Influence of solar multiple on annual solar thermal share, annual

3 solar-to-electricity efficiency and annual fossil fuel saving ratio with thermal storage 


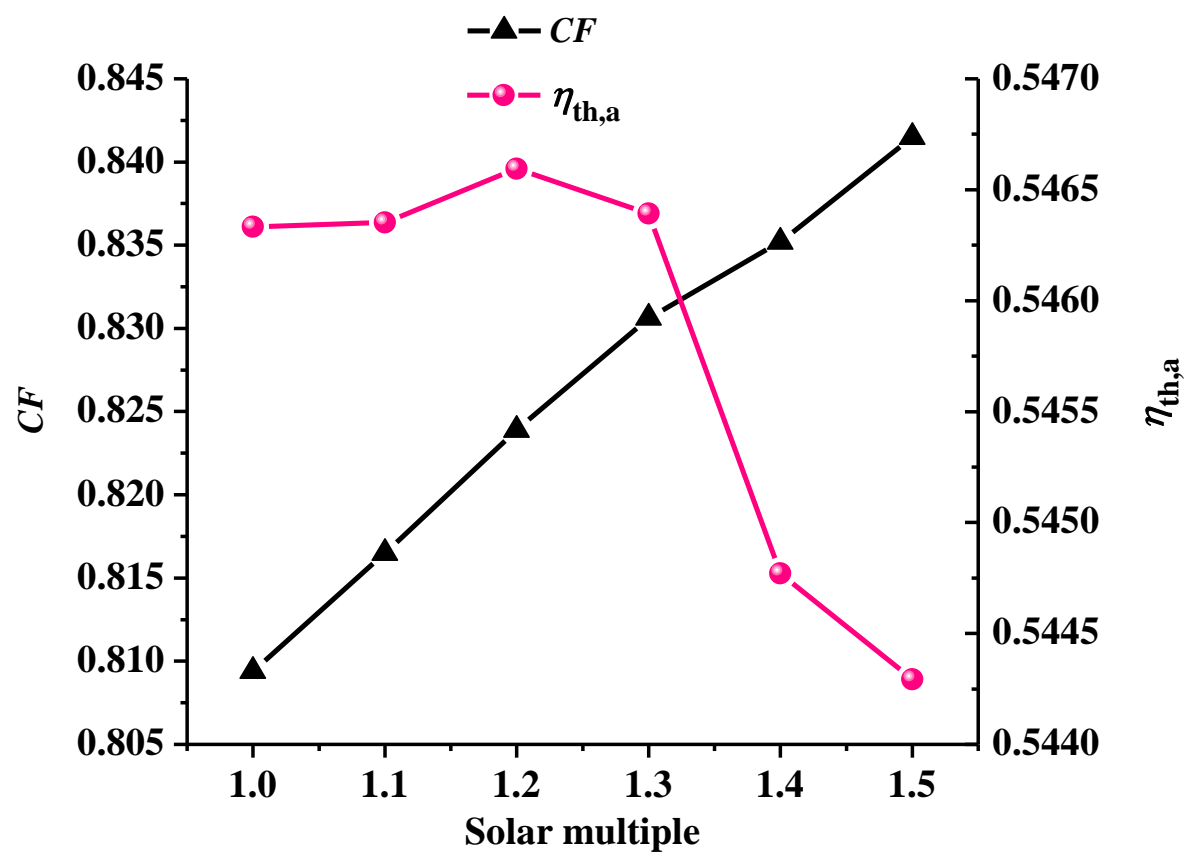

1

2 Fig. 5 Effect of solar multiple on capacity factor and annual thermal efficiency with 3 thermal storage

4 


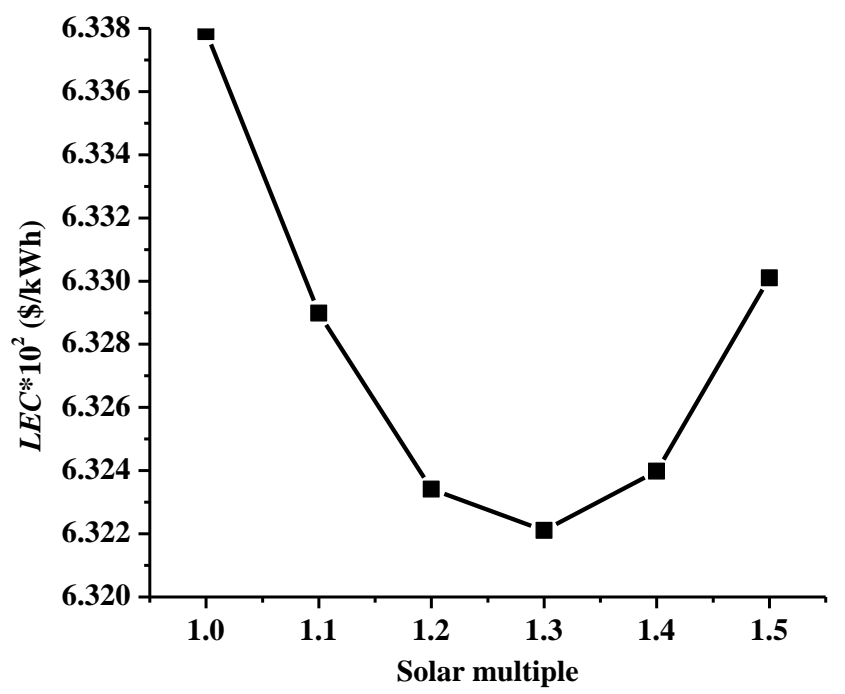

1

2 Fig. 6 Variation in levelized electricity cost for every solar multiple without thermal 3 storage

4 


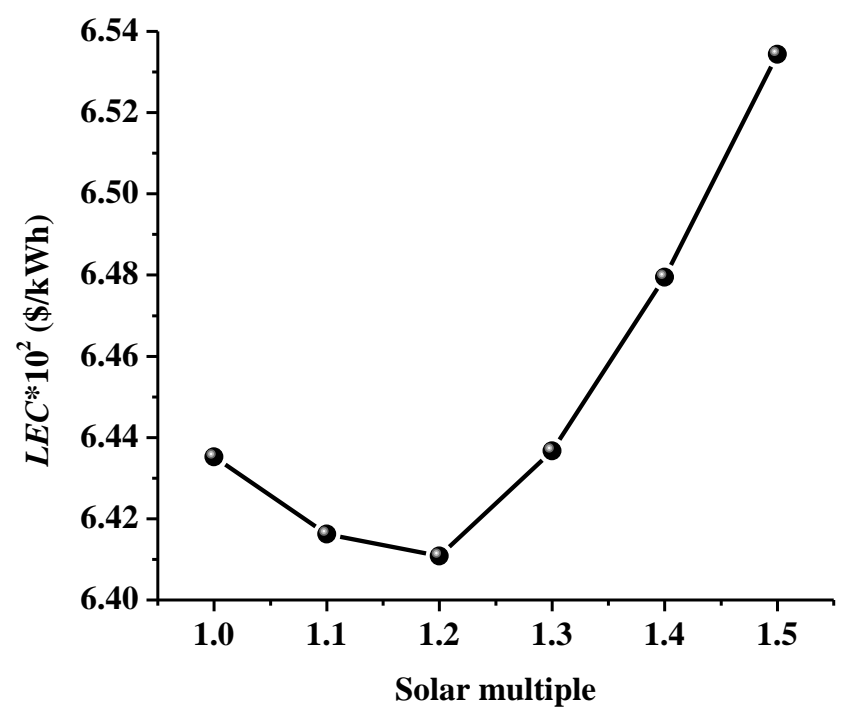

2 Fig. 7 Variation in levelized electricity cost for every solar multiple with thermal 3 storage

4

5

6 
1 Table 1. Design point parameters for the DSG solar fields of an ISCC system

\begin{tabular}{ll}
\hline Design point parameters & Yulin(China) \\
\hline Direct normal irradiance $\left(\mathrm{W} / \mathrm{m}^{2}\right)$ & 800 \\
Altitude $(\mathrm{m})$ & 1058 \\
Longitude $\left({ }^{\circ}\right)$ & 109.7 \\
Latitude $\left({ }^{\circ}\right)$ & 38.23 \\
Ambient temperature $\left({ }^{\circ} \mathrm{C}\right)$ & 25 \\
Incidence angle $\left({ }^{\circ}\right)$ & 14.78 \\
\hline
\end{tabular}

2

3 
1 Table 2. Main assumptions for the simulation and calculation

\begin{tabular}{|c|c|c|}
\hline & Parameters & Value \\
\hline \multirow{3}{*}{ Gas turbine } & Inlet temperature & $1300^{\circ} \mathrm{C}$ \\
\hline & Isentropic efficiency & $88 \%$ \\
\hline & outlet temperature & $595^{\circ} \mathrm{C}$ \\
\hline Combustor & Pressure drop (of inlet pressure) & $3 \%$ \\
\hline \multirow[t]{2}{*}{ Compressor } & Pressure ratio & 16.6 \\
\hline & Polytropic efficiency & 0.88 \\
\hline \multirow[t]{5}{*}{ Steam turbine } & HP steam pressure & 80 bar \\
\hline & HP steam temperature & $560^{\circ} \mathrm{C}$ \\
\hline & Reheat steam pressure & 16 bar \\
\hline & Reheat steam temperature & $560^{\circ} \mathrm{C}$ \\
\hline & LP steam pressure & 5 bar \\
\hline \multirow[t]{7}{*}{ HRSG } & Pinch-point temperature difference & $15^{\circ} \mathrm{C}$ \\
\hline & Cold side pressure drop in economizer & $1 \%$ \\
\hline & Cold side pressure drop in evaporator & $5 \%$ \\
\hline & Cold side pressure drop in superheater & $2 \%$ \\
\hline & Cold side pressure drop in reheater & $3 \%$ \\
\hline & $\begin{array}{l}\text { Minimum temperature difference in low-pressure } \\
\text { superheater outlet }\end{array}$ & $11^{\circ} \mathrm{C}$ \\
\hline & Minimum stack temperature & $80^{\circ} \mathrm{C}$ \\
\hline \multirow{6}{*}{$\begin{array}{l}\text { Pump } \\
\text { DSG solar } \\
\text { collector }\end{array}$} & Efficiency & $85 \%$ \\
\hline & Collector temperature at design point & $300^{\circ} \mathrm{C}$ \\
\hline & Collector efficiency at design point & 0.65 \\
\hline & Minimal temperature difference & $20^{\circ} \mathrm{C}$ \\
\hline & Pressure drop in solar steam generator & $5 \%$ \\
\hline & peak optical efficiency & 0.733 \\
\hline
\end{tabular}

2 
1 Table 3. Annual performance simulation results for ISCC-2DSG systems without 2 thermal storage

\begin{tabular}{|c|c|c|c|c|c|c|}
\hline \multirow{2}{*}{ Parameters } & \multicolumn{6}{|c|}{ Solar multiple } \\
\hline & 1.0 & 1.1 & 1.2 & 1.3 & 1.4 & 1.5 \\
\hline $\begin{array}{l}\text { Annual net electricity production } \\
{[\mathrm{GWh}]}\end{array}$ & 4001 & 4061 & 4097 & 4131 & 4162 & 4191 \\
\hline Annual fuel consumption [GWh] & 7012 & 7012 & 7012 & 7012 & 7012 & 7012 \\
\hline $\begin{array}{l}\text { Annual solar thermal energy input } \\
\text { [GWh] }\end{array}$ & 395 & 505.4 & 569.4 & 625.4 & 696.7 & 743.2 \\
\hline Annual solar thermal share [\%] & 5.333 & 6.724 & 7.51 & 8.189 & 9.038 & 9.583 \\
\hline $\begin{array}{l}\text { Annual full-load operation hours } \\
\text { [h] }\end{array}$ & 6760 & 6863 & 6924 & 6981 & 7034 & 7082 \\
\hline Capacity factor [\%] & 77.2 & 78.34 & 79.04 & 79.69 & 80.3 & 80.85 \\
\hline Annual thermal efficiency [\%] & 54.01 & 54.03 & 54.05 & 54.09 & 54 & 53.95 \\
\hline $\begin{array}{l}\text { Annual solar-to-electricity } \\
\text { efficiency }[\%]\end{array}$ & 8.375 & 10.72 & 13.03 & 14.67 & 15.35 & 16.37 \\
\hline Annual collector efficiency [\%] & 59.41 & 57.64 & 56.97 & 56 & 54.78 & 54.32 \\
\hline Annual fossil fuel saving ratio [\%] & 1.384 & 2.315 & 3.179 & 3.965 & 4.691 & 5.342 \\
\hline
\end{tabular}

3

4 
1 Table 4. Annual performance simulation results for ISCC-2DSG systems with thermal 2 storage

\begin{tabular}{lllllll}
\hline Parameters & \multicolumn{2}{l}{ Solar multiple } & & & & \\
\cline { 2 - 7 } & 1.0 & 1.1 & 1.2 & 1.3 & 1.4 & 1.5 \\
\hline Annual net electricity production & 4196 & 4233 & 4271 & 4306 & 4330 & 4362 \\
[GWh] & 7012 & 7012 & 7012 & 7012 & 7012 & 7012 \\
$\begin{array}{l}\text { Annual fuel consumption [GWh] } \\
\text { Annual solar thermal energy input }\end{array}$ & 668.7 & 735.6 & 802.4 & 869.3 & 936.2 & 1003 \\
$\begin{array}{l}\text { [GWh] } \\
\text { Annual solar thermal share [\%] }\end{array}$ & 8.706 & 9.494 & 10.27 & 11.03 & 11.78 & 12.51 \\
$\begin{array}{l}\text { Annual full-load operation hours } \\
\text { [h] }\end{array}$ & 7090 & 7152 & 7217 & 7276 & 7316 & 7371 \\
$\begin{array}{l}\text { Capacity factor [\%] } \\
\text { Annual thermal efficiency [\%] }\end{array}$ & 80.94 & 81.65 & 82.39 & 83.06 & 83.52 & 84.15 \\
$\begin{array}{l}\text { Annual solar-to-electricity } \\
\text { efficiency [\%] }\end{array}$ & 17.66 & 18.63 & 19.55 & 20.12 & 19.99 & 19.80 \\
Annual fossil fuel saving ratio[\%] & 5.45 & 6.269 & 7.112 & 7.866 & 8.369 & 9.054 \\
\hline
\end{tabular}

3

4 
1 Table 5. Cost data for economic analysis

\begin{tabular}{lll}
\hline Parameters & Value & Source \\
\hline Specific cost of gas unit $(\$ / \mathrm{kW})$ & 235 & {$[11]$} \\
Specific cost of steam unit of CC $(\$ / \mathrm{kW})$ & 860 & {$[11]$} \\
Specific cost of solar field in ISCCS-DSG $(\$ / \mathrm{kW})$ & 770 & {$[11]$} \\
Specific land cost $\left(\$ / \mathrm{m}^{2}\right)$ & 2.8 & {$[11]$} \\
Surcharge for construction, engineering and contingencies $(\%)$ & 10 & {$[10]$} \\
O\&M cost factor of gas unit $(\%)$ & 5 & {$[11]$} \\
O\&M cost factor of steam unit CC $(\%)$ & 2 & {$[11]$} \\
O\&M cost factor of solar field $(\%)$ & 1.5 & {$[11]$} \\
Interest rate $(\%)$ & 8 & {$[11]$} \\
Lifetime $(\mathrm{y})$ & 30 & {$[11]$} \\
Natural gas price $(\$ / \mathrm{GJ})$ & 7.6 & {$[11]$} \\
The price of electricity $(\$ / \mathrm{kWh})$ & 0.08 & {$[21]$} \\
Specific investment cost for thermal storage $\left(\$ / \mathrm{kWh}_{\mathrm{th}}\right)$ & 43 & {$[25]$} \\
\hline
\end{tabular}

2 